\title{
A miniaturized Microwave Bandpass Filter Based on Modified $\left(\mathrm{Mg}_{0.95} \mathrm{Ca}_{0.05}\right) \mathrm{TiO}_{3}$ Substrate
}

\author{
Mingzhe $\mathrm{HU}^{1,2}$, Zhao DING ${ }^{2, *}$, Zhiwei ZENG ${ }^{2}$, Denghui $\mathrm{JI}^{2}$ and Chunya $\mathrm{LUO}^{3}$ \\ ${ }^{1}$ College of Bigdata and Information Engineering, Guizhou University, Guiyang, Guizhou 550025, \\ China \\ ${ }^{2}$ Department of Physics and Electronics, Liupanshui Normal University, Liupanshui, Guizhou \\ 553004, China \\ ${ }^{3}$ College of Electrical Information, Huanggang Normal University, Huanggang, Hubei 438000, China
}

\begin{abstract}
A microwave miniaturized bandpass filter using $\left(\mathrm{Mg}_{0.95} \mathrm{Ca}_{0.05}\right) \mathrm{TiO}_{3}$ (abbreviated as $95 \mathrm{MCT}$ hereafter) ceramic substrate is investigated in the present paper. The paper studies the sintering and microwave dielectric properties of $\mathrm{Al}_{2} \mathrm{O}_{3}, \mathrm{La}_{2} \mathrm{O}_{3}$ and $\mathrm{SiO}_{2}$ co-doped 95MCT. The XRD pattern shows that a secondary phase $\mathrm{MgTi}_{2} \mathrm{O}_{5}$ is easily segregated in 95MCT ceramic, however, through co-doping it can be effectively suppressed, and the microwave dielectric properties, especially, the Qf value can be significantly improved. Through optimizing the co-doping ratio of $\mathrm{Al}_{2} \mathrm{O}_{3}, \mathrm{La}_{2} \mathrm{O}_{3}$ and $\mathrm{SiO}_{2}$, the sintering temperature of $95 \mathrm{MCT}$ ceramic can be lowered by $80^{\circ} \mathrm{C}$, and the microwave dielectric properties can reach $\mathrm{Qf}=61856 \mathrm{GHz}$ and $\varepsilon_{\mathrm{r}}=19.84$, which indicates the modified 95MCT ceramic have a great potential application in microwave communication devices. Based on this, we also designed a miniaturized microwave bandpass filter (BPF) on modified 95MCT substrate. Through a full wave electromagnetic structure simulation, the results show that the center frequency of the BPF is $2.45 \mathrm{GHz}$ and the relative bandwidth is $4.09 \%$ with the insertion loss of less than $0.2 \mathrm{~dB}$ in the whole bandpass.
\end{abstract}

Keywords: microwave dielectrics, doping, secondary phase, Qf value, bandpass filter

\section{Introduction}

With the rapid development of wireless communication, microwave filters have been continuously challenged with ever more stringent requirements. Higher performance, smaller size, lighter weight, and lower cost dielectric bandpass filters have become a research hotspot for recent decades [1-2]. Consequently, dielectric materials, as an important part of dielectric filters, have stimulated an intensive research effort over recent years [3-4]. As an applicable dielectric, three prerequisites have to be met, which includes near zero temperature coefficient of resonant frequency $\tau_{\mathrm{f}}$, high permittivity $\varepsilon_{\mathrm{r}}$ as well as low dielectric loss, or high quality factor Q. However, it is always a challenge to combine high $\varepsilon_{\mathrm{r}}$ and low dielectric loss in dielectrics because of the internal negatively related

*Corresponding author, email address: zding@gzu.edu.cn 
mechanisms between them.

$\mathrm{MgTiO}_{3}$ dielectric possesses an ilmenite structure with permittivity of 17 and $\tau_{\mathrm{f}}$ of -45 $\mathrm{ppm} /{ }^{\circ} \mathrm{C}$. Due to lack of $3 \mathrm{~d}$ orbit electrons, which will increase dielectric loss by participating conduction, $\mathrm{MgTiO}_{3}$ has an extremely high Qf value at microwave frequencies [5]. $\mathrm{CaTiO}_{3}$ dielectric is a well-known incipient ferroelectric dielectric with significant characteristics of large $\tau_{\mathrm{f}}\left(+800 \mathrm{ppm} /{ }^{\circ} \mathrm{C}\right)$ and large permittivity (170) [6]. Thus, their combination is expected very suitable for producing ultrahigh $\mathrm{Qf}$ and compensated $\tau_{\mathrm{f}}$ value at microwave frequencies. Actually, 95MCT possesses the optimum microwave properties [7], however, since it is a solid solution between triangle structured $\mathrm{MgTiO}_{3}$ and orthorhombic structured $\mathrm{CaTiO}_{3}$, a minor deleterious $\mathrm{MgTi}_{2} \mathrm{O}_{5}$ phase is easily segregated in 95MCT ceramics. Moreover, since the sintering temperature of 95MCT ceramics is high of $1400^{\circ} \mathrm{C}$ to $1450^{\circ} \mathrm{C}$, it is difficult for industry applications. Thus, lowing the sintering temperature as well as maintaining the excellent dielectric properties is still a challenge for 95MCT. In order to solve this problem, we employ $\mathrm{Al}_{2} \mathrm{O}_{3}, \mathrm{La}_{2} \mathrm{O}_{3}$ and $\mathrm{SiO}_{2}$ co-doping method in the present paper to lower the sintering temperature and improve the dielectric properties of 95MCT. Also, based on the modified 95MCT ceramic, a miniaturized microwave BPF was designed. Through a full wave electromagnet structure simulation, it is proved that the BPF possesses both low insertion loss and compact size.

\section{Experimental Procedure}

Samples were synthesized by conventional solid-state methods from reagent purity powders of $\mathrm{MgO}(98 \%), \mathrm{CaCO}_{3}(>98.5 \%), \mathrm{TiO}_{2}(98 \%), \mathrm{Al}_{2} \mathrm{O}_{3}(99.9 \%), \mathrm{SiO}_{2}(99.99 \%)$ and $\mathrm{La}_{2} \mathrm{O}_{3}(99.95 \%)$. The calcining process of $95 \mathrm{MCT}$ powder was carried out at $1100^{\circ} \mathrm{C}$ for $3 \mathrm{~h}$, after which, high purity $\mathrm{Al}_{2} \mathrm{O}_{3}, \mathrm{La}_{2} \mathrm{O}_{3}$ and $\mathrm{SiO}_{2}$ were added to the powder, where the doping content of $\mathrm{SiO} 2$ component was set at $0.5 \mathrm{wt} \%$, while the total content (denoted as $\mathrm{Y}$ value) of $\mathrm{Al}_{2} \mathrm{O}_{3}$ and $\mathrm{La}_{2} \mathrm{O}_{3}$ co-doping component varied but with their weight ratio being fixed as 1:1. After mixing, drying, granulating with $5 \mathrm{wt} \% \mathrm{PVA}$ and pelleting with an uniaxial pressure of $150 \mathrm{Mpa}$, the final sintering process was performed at temperatures of $1320 \sim 1400^{\circ} \mathrm{C}$ for $4 \mathrm{hrs}$ in air. The phase assemblage of specimens was examined by X-ray diffractions (D8, Brucker) using $\mathrm{CuK} \alpha(1.5406 \AA \hat{)})$ radiation and a graphite monochromator in $2 \theta$ range of $20^{\circ} \sim 80^{\circ}$. The apparent densities of the sintered pellets were directly determined by the ratio of mass and apparent volume. The permittivity $\varepsilon_{\mathrm{r}}$ and Qf value at microwave frequencies were measured by using Hakki-Coleman's dielectric resonator method and a VNA (ADVANTEST R3767C network analyzer) system.

\section{Results and Discussion}

The X-ray diffraction patterns of the as sintered 95MCT ceramics with various doping content are shown in Fig. 1. Single ilmenite solid solution forms in all specimens and they can be indexed based on $\mathrm{MgTiO}_{3}$ crystal structure (JCPDS 79-0831), which indicates $\mathrm{CaTiO}_{3}$ dissolved into $\mathrm{MgTiO}_{3}$ host. However, small amount of $\mathrm{MgTi}_{2} \mathrm{O}_{5}$-type secondary phase is also segregated in some specimens. Moreover, the crystal orientation of the modified 95MCT ceramic varies with chemical composition, suggesting an anisotropic grain growth of $95 \mathrm{MCT}$ ceramic. This phenomenon has also been observed in our previous work [8] and we believe this can be ascribed to the anisotropic interface diffusion rate in 95MCT ilmenite structure. Set (009) and (104) peaks as an example, originally, the interface diffusion energy of (104) crystal plane is higher than that of the (009) crystal plane, thus, the latter has a faster interface migration velocity. However, under the inducement of $\mathrm{Al}_{2} \mathrm{O}_{3}, \mathrm{La}_{2} \mathrm{O}_{3}$ and $\mathrm{SiO}_{2}$ liquid viscous phase, the interface diffusion energy of 
(104) crystal plane is gradually reduced and becomes energetically superior to the (009) crystal plane, resulting in the final (104) preferred orientation. And we also suggest that the chemical composition is slightly different in these 95MCT phases because the preferential crystal planes are different. The relative content of $\mathrm{MgTi}_{2} \mathrm{O}_{5}$ impurity phase can be effectively suppressed by the addition of $\mathrm{Al}_{2} \mathrm{O}_{3}, \mathrm{La}_{2} \mathrm{O}_{3}$ and $\mathrm{SiO}_{2}$. Especially in $\mathrm{Y}=1$ and 1.5 $\mathrm{wt} \%$ specimen, the $\mathrm{MgTi}_{2} \mathrm{O}_{5}$ secondary phase disappears.

Fig 2 illustrates the relative density of modified 95MCT varies with the $\mathrm{Al}_{2} \mathrm{O}_{3}$ and $\mathrm{La}_{2} \mathrm{O}_{3}$ doping content. The curve of the relative density is fitted by a Parabola Fit of with the function of $\mathrm{y}=\mathrm{A}+\mathrm{Bx}+\mathrm{Cx}^{2}$ to guide the eye. The relative density increases with $\mathrm{y}$ value and reaches a maximum value of $95.9 \%$ at $\mathrm{Y}=1.0 \mathrm{wt} \%$, then, it begins to slightly decrease with further increase of $\mathrm{Y}$ value,. Thus, the lowest pore density and the pure phase microstructure can be obtained in $\mathrm{Y}=1.0 \mathrm{wt} \%$ specimen when sintered at $1320^{\circ} \mathrm{C}$. We can conclude that $\mathrm{Al}_{2} \mathrm{O}_{3}, \mathrm{La}_{2} \mathrm{O}_{3}$ and $\mathrm{SiO}_{2}$ co-doping can effectively decrease the sintering temperature of $95 \mathrm{MCT}$ ceramic by $80^{\circ} \mathrm{C}$.
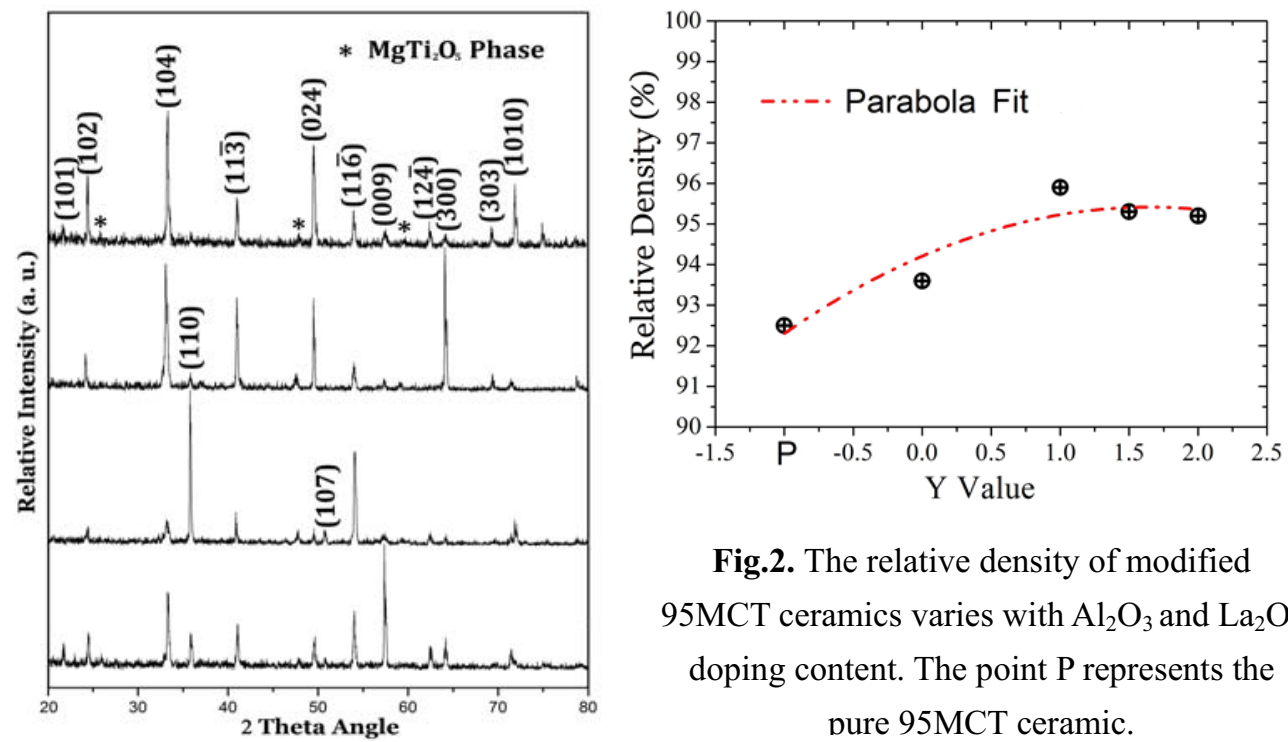

Fig.2. The relative density of modified 95MCT ceramics varies with $\mathrm{Al}_{2} \mathrm{O}_{3}$ and $\mathrm{La}_{2} \mathrm{O}_{3}$ doping content. The point $\mathrm{P}$ represents the pure $95 \mathrm{MCT}$ ceramic.

Fig.1(a) X-ray diffraction pattern of (a) $0.5 \mathrm{wt} \% \mathrm{SiO}_{2}$ doped $95 \mathrm{MCT}$, 95MCT with various doping of (b) $\mathrm{Y}=1.0 \mathrm{wt} \% \mathrm{Al}_{2} \mathrm{O}_{3}$ and $\mathrm{La}_{2} \mathrm{O}_{3}$, (c) $\mathrm{Y}=1.5 \mathrm{wt} \% \mathrm{Al}_{2} \mathrm{O}_{3}$ and $\mathrm{La}_{2} \mathrm{O}_{3}$, and (d) $\mathrm{Y}=2.0 \mathrm{wt} \% \mathrm{Al}_{2} \mathrm{O}_{3}$ and $\mathrm{La}_{2} \mathrm{O}_{3}$. All samples were sintered at $1320^{\circ} \mathrm{C}$. 


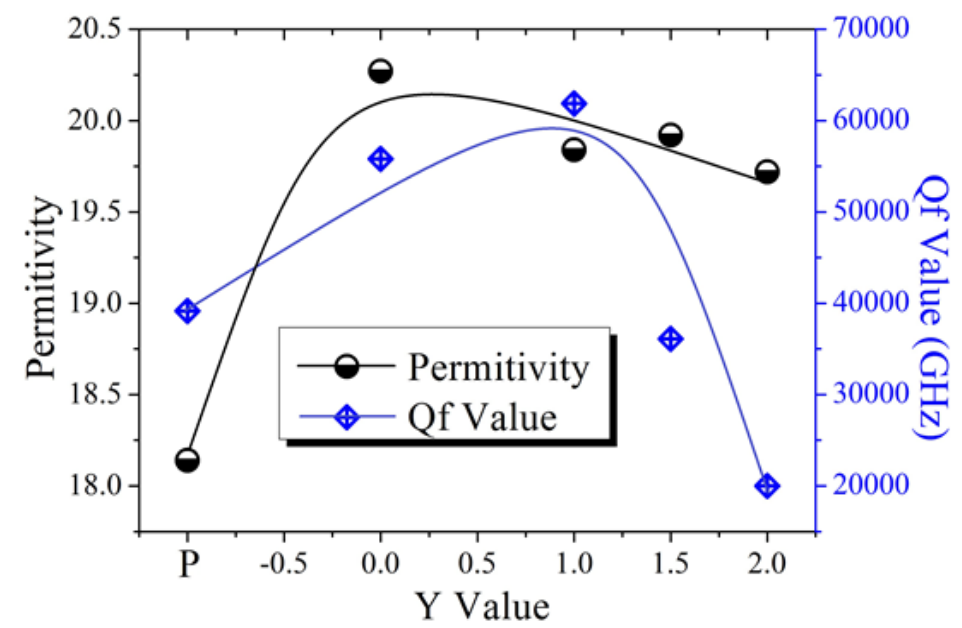

Fig.3. The relationship between permittivity and Qf value of modified $95 \mathrm{MCT}$ with with $\mathrm{Al}_{2} \mathrm{O}_{3}$ and $\mathrm{La}_{2} \mathrm{O}_{3}$ doping content. The point $\mathrm{P}$ represents the pure $95 \mathrm{MCT}$ ceramic.

Fig.3 shows the dielectric properties, including the permittivity $\varepsilon_{\mathrm{r}}$ and the Qf value of modified 95MCT. As can be observed, the Qf value firstly increases with the increase of $y$ value until it reaches the maximum value of $61856 \mathrm{GHz}$ at $\mathrm{Y}=1.0 \mathrm{wt} \%$, and then it decreases sharply as Y further increases. Actually, the variation of Qf value in microwave dielectrics is quite complicated and is influenced by many factors, such as anharmonic phonon vibration, order-disorder transformation, pore density, grain size distribution, oxygen vacancy and impurity phases. Since the matrix composition of these 95MCT ceramics is the same, we suggest that the pore density and impurity phase are the two deciding factors of the Qf value. When the doping content of $\mathrm{SiO}_{2}$ is $0.5 \mathrm{wt} \%$, and y value is not larger than one, the relative density is obviously improved and no impurity phase is detected by XRD, thus, the Qf value increases from $39160 \mathrm{GHz}$ of the pure 95MCT to $61856 \mathrm{GHz}$ at $\mathrm{Y}=1.0 \mathrm{wt} \%$. However, when $\mathrm{Y}$ further increases, the relative density decreases and impurity phase appears at $Y=2.0$, resulting in the sharply decrease of $\mathrm{Qf}$ value, which is consistent with the common recognition that pore density and impurity phase are fatal factors for high Q microwave ceramics [9]. The $\varepsilon_{\mathrm{r}}$ is also decided by the relative density and impurity phase, however, it is much more sensitive to the latter. When $0.5 \mathrm{wt} \% \mathrm{SiO}_{2}$ is doped, the relative density increases, causing an increase in permittivity at the first stage. However, since $\mathrm{SiO}_{2}, \mathrm{Al}_{2} \mathrm{O}_{3}$ or $\mathrm{LaAlO}_{3}$ are all low permittivity composition, one can see that when the $\mathrm{Y}$ value is larger than zero, the permittivity begins to decrease because the chemical composition factor outweighs the relative density factor. The highest dielectric constant of 20.27 is obtained at $Y=0$ point.

Comprehensively considering the dielectric properties of modified 95MCT ceramic, we employ the $\mathrm{Al}_{2} \mathrm{O}_{3}$ and $\mathrm{La}_{2} \mathrm{O}_{3}$ modified $95 \mathrm{MCT}$ substrate with $\mathrm{Y}=1.0$ for designing a miniaturized bandpass filter for RFID application. The filter can be viewed as a two-port network and its admittance matrix is described as:

$$
Y=\left[\begin{array}{ll}
\mathrm{y}_{11}(s) & \mathrm{y}_{12}(s) \\
\mathrm{y}_{21}(s) & \mathrm{y}_{22}(s)
\end{array}\right]=\mathrm{j}\left[\begin{array}{ll}
0 & \mathrm{~K}_{0} \\
\mathrm{~K}_{0} & 0
\end{array}\right]+\sum_{k=1}^{N} \frac{1}{\left(s-j \lambda_{k}\right)}\left[\begin{array}{ll}
r_{11 k} & r_{12 k} \\
r_{21 k} & r_{22 k}
\end{array}\right]
$$

In the two-port network, the coupling matrix $\mathrm{M}$ includes two coupled cavities resonator 
and the coupling between the source and load ports. The physical structure of the miniaturized BPF can be depicted as in Fig.4. The BPF includes two zigzag resonators, with the substrate parameters being: the permittivity $\varepsilon_{\mathrm{r}}$ of 19.84 and the tan $\delta$ being 0.00004 at working frequency. The perimeter of the both resonators is $16 \mathrm{~mm}$, with the strip width being $1.732 \mathrm{~mm}$. The angle $\theta$ is ranged from $60^{\circ}$ to $85^{\circ}$. The width of input and output strips marked as red in Fig. 4 is $1 \mathrm{~mm}$. The splits of the two resonators are both $1 \mathrm{~mm}$ and the distance between the two resonators is $0.642 \mathrm{~mm}$. Employing the zigzag microstrip in the $\mathrm{BPF}$, a parasitism compactor can be introduced at the angel $\theta$, which can further contract the electrical length of the resonators. Fig5 illustrates the simulated results of the $\mathrm{S}$ scattering parameters, including reflection coefficient S11 and transmission coefficient S21, of the designed dielectric BPF. The center frequency of the BPF is $2.45 \mathrm{GHz}$ with the relative bandpass of $3 \mathrm{~dB}$ being $4.09 \%$. Also, we notice that a very high-efficiency transmission is achieved in the present BPF, in which the reflection coefficient $\mathrm{S} 11$ is smaller than $-20 \mathrm{~dB}$ in the frequency range from $2.4091 \mathrm{GHz}$ to $2.2464 \mathrm{GHz}$. The transmission loss is less than $0.2 \mathrm{~dB}$ during the whole bandpass. The maximum transmission coefficient reaches $-0.18 \mathrm{~dB}$ at $2.4312 \mathrm{GHz}$ and the $-3 \mathrm{~dB}$ operating frequency range is from $2.3784 \mathrm{GHz}$ to $2.4768 \mathrm{GHz}$. Moreover, due to the source load coupling, an additional transmission zero can be introduced, owing to which, the BPF possesses high square ratio and the out-of-band rejection properties are significantly enhanced. As a result, in the frequency range of $\mathrm{f}_{0} \pm 40 \mathrm{MHz}$, the transmission loss is greater than $20 \mathrm{~dB}$, indicating a good suppression of noise signal.

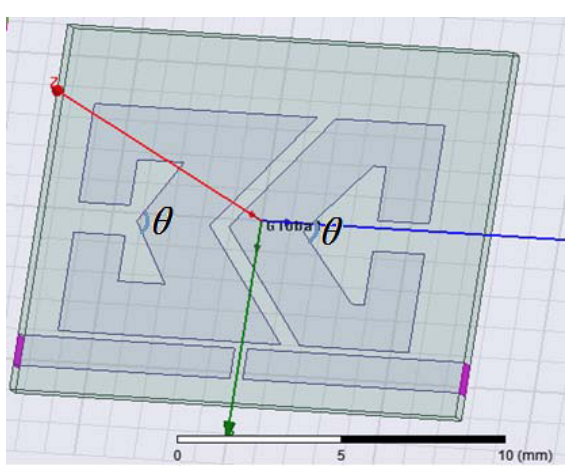

Fig.4. The structure of the dielectric

BPF with two zigzag ring resonators.

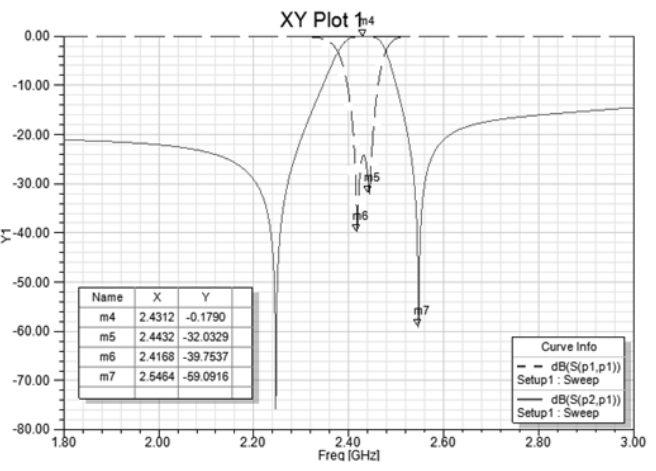

Fig.5. The simulated results of the $\mathrm{S}$ scattering parameters of the above zigzag BPF with the angle $\theta$ being $85^{\circ}$.

\section{Summary}

In this article, we have employed the modified 95MCT to design a compact BPF for RFID application. The sintering behavior as well as the microwave dielectric properties of 95MCT ceramic can both be well improved through co-doping of $\mathrm{Al}_{2} \mathrm{O}_{3}, \mathrm{La}_{2} \mathrm{O}_{3}$ and $\mathrm{SiO}_{2}$ sintering aids. The preferable crystal plane of $95 \mathrm{MCT}$ varies with the co-doping content. When the doping content of $\mathrm{Al}_{2} \mathrm{O}_{3}, \mathrm{La}_{2} \mathrm{O}_{3}$ and $\mathrm{SiO}_{2}$ component are all of $0.5 \mathrm{wt} \%$, the microwave dielectric properties of $\mathrm{Qf}=61856 \mathrm{GHz}$ and $\varepsilon_{\mathrm{r}}=19.84$ can be obtained in 95MCT ceramic when sintered at $1320^{\circ} \mathrm{C}$ for $4 \mathrm{hrs}$. Based on this, we propose a novel and compact BPF structure. Through full wave numerical simulation, the results show that the center frequency locates at $2.45 \mathrm{GHz}$ with the relative bandpass of $4.09 \%$ and a very high-efficiency transmission property is achieved with the insertion loss being less than $0.2 \mathrm{~dB}$ during the whole bandpass, which indicates the present BPF has potential 
applications in RFID industry.

\section{Acknowledgment}

The present work is partially supported by the National Science Foundation of China No.51567017, partially supported by Physical Electronic Key Discipline of Guizhou Province No. ZDXK201535, partially supported by the Key Project of the Education Department of Guizhou Province(No.2013174), partially supported by the Natural Science Foundation of Guizhou Province(No.20132092), partially supported by the Postdoctoral Science Foundation of China (No.2014M562342), partially supported by the Outstanding Young Scientist Cultivation Program of Guizhou Province No.201522, partially supported by the Joint Science Foundation of Liupanshui City and Guizhou Province No. LH20147448, partially supported by the Key Laboratory of Opt-electrical Information Technology of Liupanshui City (No.52020201420205), partially supported by the MIT Creative Team of Liupanshui Normal University No.LPSSYKJTD201402, partially supported by the Recruitment Program of Liupanshui Normal University No. LPSSYKYJJ201403 and partially supported by the Recruitment Program of Guizhou University No.2012032.

\section{References}

1. E. Arabi, M. Lahti, T. V. Heikkilä, A. Shamim, A 3-D Miniaturized High Selectivity Bandpass Filter in LTCC Technology, Microwave and Wireless Components Letters, IEEE, 24(2014)8

2. Jian Xin Chen, Yang Zhan, Wei Qin, Zhi-Hua Bao, Quan Xue, Novel Narrow-Band Balanced Bandpass Filter Using Rectangular Dielectric Resonator, Microwave and Wireless Components Letters, IEEE, 25(2015)289

3. Wen Lei, Wenzhong Lu, Jianhua Zhu, Xiaohong Wang, Microwave dielectric properties of $\mathrm{ZnAl}_{2} \mathrm{O}_{4}-\mathrm{TiO}_{2}$ spinel-based composites. Materials Letters, 61(2007)4066

4. Mingzhe $\mathrm{Hu}$, Jun Qian, Structure evolution and microwave dielectric response of $\left(\mathrm{Ca}_{0.5+\mathrm{x}} \mathrm{Sr}_{0.5-\mathrm{x}}\right)\left[\left(\mathrm{Al}_{0.5} \mathrm{Nb}_{0.5}\right)_{0.5} \mathrm{Ti}_{0.5}\right] \mathrm{O}_{3}$ solid solutions, Cur. Appl. Phys., 14 (2014) 46

5. W. Wersing, in:B.C.H.Steele(Ed.), Electronic Ceramics, Elsevier, London. (1991) 67

6. K. Wakino, Recent development of dielectric resonator materials and filters in Japan, Ferroelectric 91 (1989) 69.

7. V. M. Ferreira, F. Azough, R. Freer, J.L. Baptista, The effect of $\mathrm{Cr}$ and $\mathrm{La}$ on $\mathrm{MgTiO}_{3}$ and $\mathrm{MgTiO}_{3}-\mathrm{CaTiO}_{3}$ microwave dielectric ceramics, J. Mater. Res. 12 (1997) 3293.

8. Mingzhe Hu, Juan Xiong, Haoshuang Gu, Yihang Chen, Yu Wang, Low Temperature Cofirable $\mathrm{Ca}\left[\left(\mathrm{Li}_{1 / 3} \mathrm{Nb}_{2 / 3}\right)_{0.95} \mathrm{Zr}_{0.15}\right] \mathrm{O}_{3+\delta}$ Microwave Dielectric Ceramic with $\mathrm{ZnO}-\mathrm{B}_{2} \mathrm{O}_{3}-\mathrm{SiO}_{2}$ Frit. Ceram. International , 38(2011)3175

9. M.Valant, D.Suvorov, C. J.Rawn, Intrinsic Reasons for Dielectric Properties of $\mathrm{Ba}_{6-3 \mathrm{x}} \mathrm{R}_{8+2 \mathrm{x}} \mathrm{Ti}_{18} \mathrm{O}_{54}(\mathrm{R}=\mathrm{La}-\mathrm{Gd})$ Solid Solutions, Jpn. J. Appl. Phys, 38(1999)2820 